This item was submitted to Loughborough's Research Repository by the author.

Items in Figshare are protected by copyright, with all rights reserved, unless otherwise indicated.

\title{
A hub service: extending the support provided by one institution to students of other local institutions
}

PLEASE CITE THE PUBLISHED VERSION

http://dx.doi.org/10.11120/msor.2013.13010018

PUBLISHER

(C) Higher Education Academy

VERSION

VoR (Version of Record)

LICENCE

CC BY-NC-ND 4.0

REPOSITORY RECORD

Trott, Clare, Simon Drew, and H. Maddocks. 2019. "A Hub Service: Extending the Support Provided by One Institution to Students of Other Local Institutions". figshare. https://hdl.handle.net/2134/10647. 
This item was submitted to Loughborough's Institutional Repository (https://dspace.lboro.ac.uk/) by the author and is made available under the following Creative Commons Licence conditions.

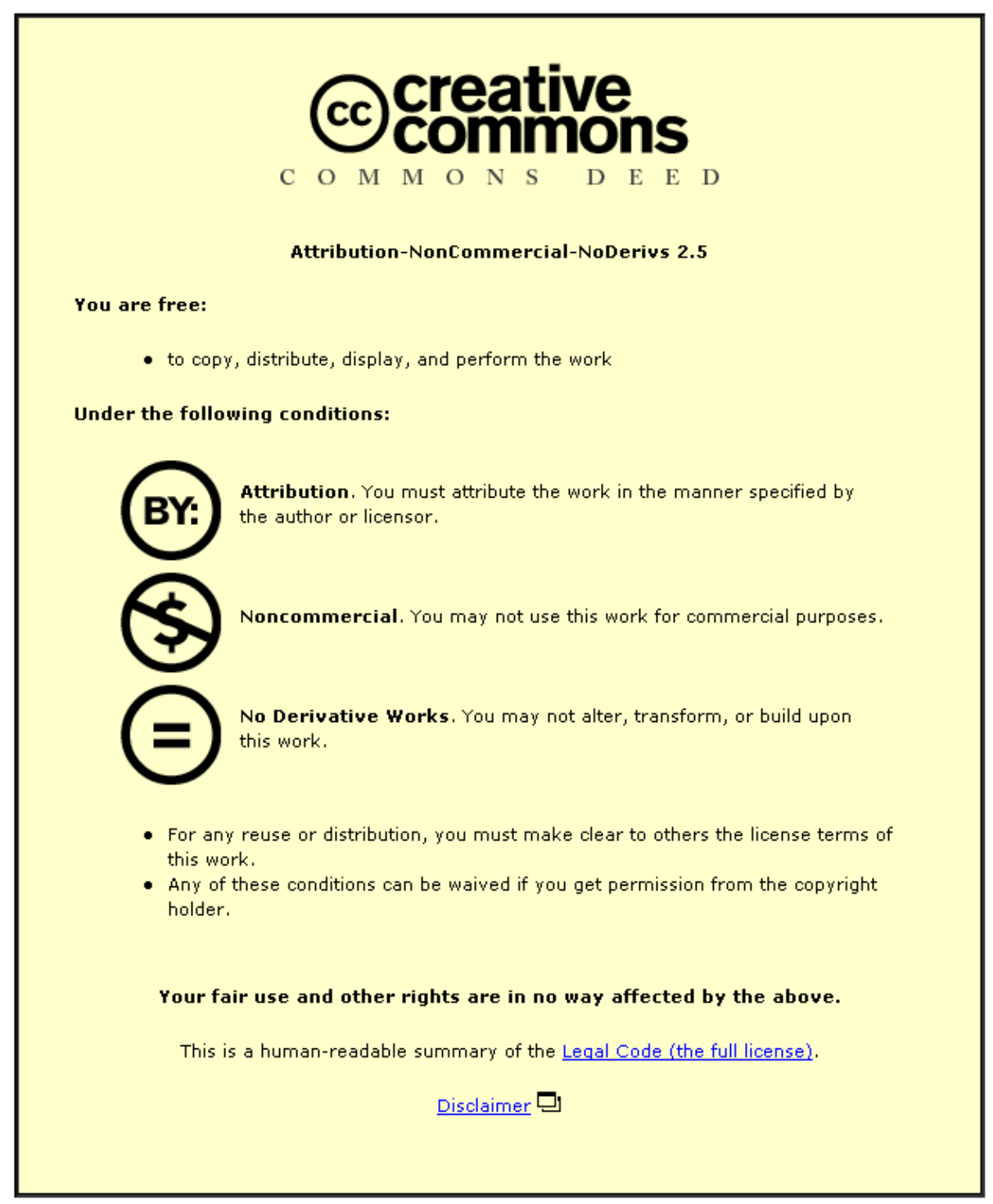

For the full text of this licence, please go to: http://creativecommons.org/licenses/by-nc-nd/2.5/ 


\title{
A Hub Service: Extending the Support Provided by One Institution to Students of Other Local Institutions
}

\author{
C. Trott, S. Drew \& H. Maddocks \\ Loughborough University, UK
}

Corresponding author:

Clare Trott, Mathematics Education Centre, Loughborough University, Loughborough LE11 3TU, UK

Email: C.Trott@Iboro.ac.uk, Phone: +44(0)1509 228258

\begin{abstract}
We report on the experience of Loughborough University's Eureka Centre for Mathematical Confidence in establishing a small pilot project to provide one-to-one mathematics support for neurodiverse students who attend other local universities and where no such provision is available. We outline the background to the scheme and report on the three students involved.
\end{abstract}

Keywords: mathematics support, neurodiverse students, dyslexia, dyscalculia

\section{The Loughborough Experience}

The Eureka Centre for Mathematical Confidence is part of the Mathematics Education Centre (MEC) at Loughborough University, which in 2005 was awarded, with Coventry University, Centre for Excellence in Teaching and Learning (CETL) status in recognition of its sustained and excellent contribution in the field of university-wide mathematics support. This encompasses support for students with additional needs. Within this framework, the role of the Eureka Centre is to provide one-to-one mathematics support to neurodiverse students. The staff in the Eureka Centre have built up considerable expertise in supporting students with dyscalculia, dyslexia, dyspraxia and other neurodiversities with the numerical, mathematical and statistical demands of their courses.

Dyslexia is:

'characterised by difficulties with phonological processing, rapid naming, working memory, processing speed and the automatic development of skills that may not match up to an individual's other cognitive abilities. It tends to be resistant to conventional teaching methods, but its effects can be mitigated by appropriately specific intervention ...' (BDA 2007).

More specifically, a dyslexic student studying mathematics may:

- struggle to read accompanying text or have slower reading speed than their peers, 
- have difficulty understanding what is required of them from instructions,

- find it more difficult to structure logical solutions and reports,

- make more frequent transcription errors,

- appear disorganised with poorly presented work.

Further difficulties may arise from issues with working memory that impact on the recall of information and numerical facts as well as remembering notation, particularly, which character represents which variable. This will clearly have implications for revision and examinations.

Dyscalculia:

'affects the ability to acquire arithmetical skills. Dyscalculic learners may have difficulty understanding simple number concepts, lack an intuitive grasp of numbers, and have problems learning number facts and procedures. Even if they produce a correct answer or use a correct method, they may do so mechanically and without confidence' (DfES 2001).

Expanding on this, Trott (2009, p127) says:

'The mathematical difficulties students may face include understanding and using mathematical concepts and relations. They may struggle with mathematical symbols or digits and have difficulty in performing specific mathematical operations.'

A dyscalculic student is likely, therefore, to have fundamental difficulties with understanding number, operations and the inter-relationships between numbers.

For students who find their mathematics or statistics challenging due to their neurodiversity, there is frequently an associated high mathematical anxiety.

In contrast to the earlier mentioned, the neurodiverse student enhances the learning environment with many strengths. A dyslexic student tends to bring creativity with holistic thinking, enabling them to be insightful and good problem solvers, while the dyscalculic student may also be creative and resourceful as well as having excellent literacy skills.

Drawing on the extensive experience of the work of the Eureka Centre at Loughborough University, a pilot project was established that would enable dyscalculic or dyslexic students with mathematical difficulties to access the support available at Loughborough and which does not exist in their own institutions.

\section{The Pilot Project}

Under the pilot scheme, the Midland Region Dyscalculia Centre was set up at Loughborough University, within the Eureka Centre for Mathematical Confidence and this initiative was funded by the Higher Education (HE) STEM Programme through the Sigma network. The centre's team of experienced tutors aimed to help dyscalculic and dyslexic students overcome their barriers in numeracy, mathematics and statistics-based courses by providing support with: a range of study skills in mathematics, including the understanding of number and numerical operations, relationships between numbers, graphical and algebraic skills, strategies to aid memory for mathematical facts, reading support for mathematics tasks that embed notation within text, writing mathematical and statistical solutions and reports, and in exploring revision techniques. The objectives are to enable the student to increase their mathematical confidence, reduce the associated anxiety and achieve academic success, becoming independent in their learning. 
The proposed pilot scheme anticipated that a student should expect to come to the centre in Loughborough for a small number of sessions lasting 2.5 hours each. This would allow for two separate hours of one-to-one support, with a 30-minute break between. More than this in one session would likely create overload, particularly for the neurodiverse student.

Learning support tutors in other Midland Universities were made aware of the pilot project through a Jiscmail list for the Association of Dyslexia Specialists in Higher Education (ADSHE) and were asked, in the first instance, to contact the Eureka Centre. The pilot was open to students with a formal identification of dyslexia or dyscalculia and who required mathematics or statistics support for their course of study with which they were struggling as a result of their neurodiversity. Learning support tutors were asked to recommend students who they felt would benefit from support at the centre. It was made clear that the centre could not provide support for final year students nor provide screening or assessment for dyscalculia. The learning support tutors were asked to provide us with as many details as possible about the student, including their neurodiverse profile and any additional requirements the student had, their name, course and year and some details of the mathematical, statistical and numerical needs of the student.

Students were advised that during the first hour they would meet with the tutor, talk through their needs and the mathematical aspects of their course, identifying key areas and then make a start. They were reminded about the need to keep appointments, as far as possible, and bring with them their mathematics notes, handouts and task sheets as well as their calculator. If a student used specialist software or assistive technology, they were additionally asked to bring their laptop.

There was much interest in the pilot project and, eventually, three students took part in the scheme. This was as intended, a limited pilot scheme. Many of those who were initially interested, were unable to access the centre due to issues of location, travel and time.

\section{The Students}

This section will give more specific details of the three students who took part in the pilot for the Midland Region Dyscalculia Centre project.

\section{Student 1: 'Ian'}

lan is a young undergraduate at the end of his second year, studying Construction Management at a Midlands university. He is soon to begin a third year of work placement. He has been identified with dyslexia, and as a result has difficulties with mathematics, and needed one-to-one support to pass a mathematics module examination that he was retaking.

lan's specific mathematics issues are consistent with a 'typical' dyslexia profile. Whereas he has a sound understanding of numerical concepts and excellent visual spatial skills, his poor organisation of work and the inability to break down problems into appropriate steps leads to notable difficulties in algebra and applying formulae, e.g. trigonometry. Arithmetic was not such a problem as lan is able to use a calculator correctly and appropriately. $\mathrm{He}$ knows his numerical weaknesses and when to check his mental arithmetic. In all lan's examinations, calculators are permitted.

Initial support targeted the layout of questions and the use of colour to separate algebraic terms. As negative numbers were proving to be a particular issue, this helped lan associate the corresponding sign with the correct term. Although the use of colour was clearly helping lan manipulate mathematical constructs, it was frustrating that it took him a long time to use the technique himself without prompting. 
Due to his dyslexia, lan found it very difficult to retain facts across sessions. Despite demonstrating within the same session that learning had taken place, lan found it difficult to retain that knowledge to the next meeting.

lan had a number of support sessions over a period of 13 weeks. Travel was not a problem for lan and he clearly benefitted from the support, passing his re-sit examination and will now proceed to his final academic year after his work placement.

\section{Student 2: "Fiona"}

Fiona is a mature foundation student of Wildlife and Countryside Management at a Midlands rural agricultural college. She has been identified with dyscalculia, but is otherwise extremely bright with a determined and open personality. Fiona has just come to the end of her foundation course, and hopes to enrol on to the BSc programme.

At the time of support, Fiona was struggling with handling statistics using Excel spreadsheets. As a mature student she was dealing with computer literacy as well as the mathematical issues raised by her dyscalculia. The support offered included helping her to understand the potential and controls of Excel, and to help her grasp the reasons why statistics is employed to demonstrate real-life behaviour.

Fiona has a strong need to relate to data in a tangible and personal way. Her requirements go beyond contextualisation, as she needs to collect data herself and perceive it with her own senses. When she is in woodland counting fauna and flora, and observing natural characteristics, she has an understanding of the behaviours as strong as any other student. But Fiona struggles to comprehend the reasons for quantifying the real world and to represent it graphically. Whereas most observers find a bar chart or scatter graph useful in showing a real-life trend, Fiona does not visualise a graphical representation in the same way, and therefore questions the need for it.

Support, over two sessions (four hours in total) was given in helping Fiona with preparing for a re-sit of a statistics module examination. Her lecturer had been helpful in providing a full solution of the previous examination, which offered the basis for talking through what the questions were asking for, and how Excel could be used to manipulate data to demonstrate the required answers. Fiona always questioned every suggestion, which made her an ideal student. Her honest and curious approach made it easier to address the formative assessment of learning.

By stressing inclusion of difference, Fiona began to appreciate how others may prefer visual abstract representations of data, even if it is not helpful to her. By keeping the charts simple, and corresponding exactly to the question being asked (with as little interpretation as possible), Fiona was able to glimpse at how these graphs could represent real life trends. With this embryonic conceptualisation, she was therefore able to accept some procedural tasks as an end to a means.

\section{Student 3: 'Sarah'}

Sarah is dyslexic and was on a foundation course in Sports Horse Management and Training at a Midlands university. She wanted to do the third year BSc Equine Sports Science course starting in the autumn. She needed to pass a two week statistics summer school to do this and had not previously studied statistics. Her only previous Mathematics was the Foundation GCSE course where she obtained a grade $\mathrm{C}$. There is very little statistics in this course and it was quite a few years ago. 
After some discussions, three dates were agreed for Sarah to attend the centre for some statistics support. As it later transpired, only two slots proved possible. The times were agreed so that it fitted in well with the student's journey between university and home. However, one of the issues it highlighted was the difficulty with arranging times that are suitable for both student and staff when they are not from the same institution.

Sarah sent the tutor the course outlines to give an indication of what she would be expected to do in the summer school. As she is dyslexic Sarah finds directions particularly difficult. She had found directions to the university from the Internet but when she wrote them in an email for the tutor to check, as she was very unsure of finding her way to Loughborough, the directions did not make sense. Eventually this was resolved.

At the initial session, it transpired that Sarah really had no idea of any statistics, so the student and the tutor had to start at the beginning with measures of central tendency and word association with these, trying to aid working memory by connecting the name with the concept. She also had no idea of any type of statistical diagram and the use of these diagrams. Further coverage of material, including the idea of standard deviation and what it was used for, and the shape and characteristics of the normal distribution, was too much new work, especially for a dyslexic, and there was little time to consolidate. A series of coloured diagrams showing the various topics covered in the session was helpful for Sarah to take away. Another session soon afterwards would have been more beneficial, but unfortunately circumstances dictated the time available.

The next session with Sarah was after the summer school but before she had to submit her statistics coursework. Sarah said that without the previous session she would not have been able to access the summer school as the lecturer assumed previous knowledge.

In this second session Sarah worked with her tutor on SPSS. She was just able to use it but the analysis was very difficult for her. Sarah and her tutor talked through what her results showed and how she should structure the report, using a flow chart. Sarah wrote the analysis for one of her hypotheses whilst she was in the session to check she was able to interpret the results logically. For this work, there were strict conventions on how to structure and present tables, particularly with reference to the grid indicating which cells had to be merged and which did not. This meant that some cells in the results were not boxed in, although still needing to be aligned, and were thus made particularly difficult for Sarah to read due to her dyslexia.

Without the support given Sarah would not have been able to complete the summer school, thus she would not be able to continue with her chosen route in her studies. She had achieved a 2:1 in her Foundation course and was academically able to move onto the course she had chosen. Sarah is also looking to Loughborough to provide some statistics support for her next academic year and would be more than willing to try using a computer link and microphones (e.g. Elluminate ${ }^{\circledR}$, http://www.elluminate.com), to avoid the issues with travelling.

\section{The Future}

During this pilot phase, the Eureka Centre for Mathematical Confidence has supported three students with a range of neurodiverse profiles and mathematical requirements. These have included breaking down problems into smaller, more manageable steps, aiding working memory by using colour to identify terms and the retention of facts in preparation for examinations and handling statistics. The latter including understanding why we use statistics, linking names and concepts and structuring statistical reports. Students and tutors also worked with Excel and SPSS packages. 
There were, of course, difficulties that arose in terms of geography as well as the provision of support for students from other institutions. This included difficulties in arranging mutually convenient times for student and tutor as well as travel problems experienced. Having ready access to materials meant that students needed to forward these to the tutor. Additionally, it was noted that there was less time for consolidation and, because sessions may be less frequent, students with working memory issues could struggle.

However, on the positive side, the students had access to specialist support that was not available in their own institutions and were able to talk through the issues they had. All the students clearly progressed and found it beneficial, not least in so far as lan and Sarah are successfully moving forward on their courses and Fiona is currently awaiting her results. In particular, for Fiona, a dyscalculic student, there was evidence of 'embryonic conceptualisation.'

For the future, the Eureka Centre would very much like to continue to develop this small but worthwhile project and perhaps investigate the use of Elluminate ${ }^{\circledR}$ as a means of avoiding some of the issues that arose with travel and timings.

\section{References}

British Dyslexia Association (BDA) (2007) Dyslexia Research Information. http://www. bdadyslexia.org.uk/about-dyslexia/further-information/dyslexia-research-information-.html (accessed 6 July 12).

Department for Education and Skills (DfES) (2001) The National Numeracy Strategy. Guidance to support pupils with dyslexia and dycalculia. DfES 0512/2001. http://scotens.org/ sen/resources/dyslexia_leaflet_maths.pdf (accessed 26 October 2012).

Trott, C. (2009) Dyscalculia. In Neurodiversity in Higher Education: Positive Responses to Specific Learning Differences (ed. D. Pollak), pp125-148. Chichester, UK: John Wiley \& Sons. 